\title{
O desemprego e as tendências da contrarreforma no campo dos direitos sociais \\ Unemployment and counter-reform trends in the field of social rights
}

\author{
ANGÉLICA LUIZA SILVA BEZERRA*
}

MiLena GOMES DE MedeIRos**

RESUMO - Procura-se apreender algumas determinações presentes na dinâmica atual da contrarreforma no campo dos direitos sociais no século XXI, no Brasil, dando destaque, sobretudo, à ressignificação jurídico-política posta pela mediação da flexibilização e pela precarização das condições e relações de trabalho, aviltadas como resposta ao desemprego.

Palavras-chave - Contrarreforma. Direitos sociais. Desemprego. Flexibilização.

ABSTRACT - It seeks to apprehend some determinations that appear in the current dynamics of the counter-reform in the field of social rights in the XXI century, in Brazil, highlighting, above all, the legal and political resignification posed by the mediation of flexibilization and precarization of conditions and labor relations, debased while response to unemployment.

Keywords - Counter-reform. Social rights. Unemployment. Flexibilization.

\footnotetext{
* Doutora em Serviço Social. Professora Adjunta da Universidade Federal de Alagoas, - Unidade Educacional de Palmeira dos Índios/Brasil. CV: http://lattes.cnpq.br/1305340622803849. E-mail: angelicamcz@yahoo.com.br.

${ }^{* *}$ Doutora em Serviço Social. Professora Adjunta do curso de Serviço Social - FSSO da Universidade Federal de Alagoas (UFAL). CV: http://lattes.cnpq.br/8188671316681752. E-mail: milena.medeiros@fsso.ufal.br. Submetido em: novembro/2017. Aprovado em: setembro/2018.
} 
esde o final dos anos 1990 a situação econômica e política, devido aos processos de crise dos anos de 1970/1980, acentuou a incerteza no seio de uma geração, que cresceu num contexto econômico de melhoria do nível de vida, e que foi confrontada com a deterioração das condições de trabalho, a precariedade e o subemprego, após a intensa crise e a reestruturação mundializada do capital.

A análise dos fundamentos deste cenário deve ser buscada no aprofundamento das contradições sociais fundamentais do próprio sistema do capital, que indica transformações tanto no trabalho quanto na vida social, engendradas pelo ciclo de contrarreformas inaugurado pelo neoliberalismo.

Nos últimos anos, o chamado mundo do trabalho ${ }^{1}$ vem sofrendo mudanças significativas com a alteração da organização da gestão do trabalho, em nome do desenvolvimento econômico e social. Esta realidade não é apenas uma particularidade da América Latina, mas abrange os países centrais, colocando em evidência contradições inéditas na história, na forma do desemprego crônico e da precarização do trabalho e acirrando as sequelas da chamada questão social.

Reafirmam-se os preceitos neoliberais, pois, em essência, o neoliberalismo baseado no uso sistemático do poder do Estado, sob o véu ideológico da "não intervenção", impõe um projeto hegemônico de recomposição da ordem capitalista que, através de políticas econômicas e sociais oferecidas pelos organismos financeiros para os estados nacionais, tenta compatibilizar desenvolvimento econômico com desenvolvimento social e sustentabilidade ambiental.

No atual debate, as formas de enfrentamento à pobreza pelo Estado desistoriciza seus fundamentos, tornando evidente a permanência de sua naturalização, psicologização e criminalização. No caso do desemprego, isso se dá nas mais diversas formas de inserções e ocupações - garantidas e legitimadas até mesmo pelo Ministério do Trabalho e Previdência, no caso brasileiro.

Esta realidade, que garante a resposta do Estado sobre o campo dos direitos sociais e trabalhistas, revela um direcionamento regressivo e destrutivo para a classe trabalhadora como um todo, pois, em nome da estabilidade econômica e social, tornou-se central o investimento em políticas que possam garantir a inserção de trabalhadores em atividades remuneradas, seja de forma empreendedora, seja pela via da terceirização. Em outras palavras, os serviços públicos precários, realizados por serviços mal remunerados e terceirizados, numa espécie de institucionalização do trabalho em condições análogas às de escravo.

Desse modo, mantém-se uma íntima articulação com as necessidades da acumulação capitalista, seja do ponto de vista econômico, transformando ex-trabalhadores assalariados e socialmente protegidos em trabalhadores autônomos, terceirizados ou simples produtores de mercadorias, integrados às atuais estratégias de gestão da produção; seja socializando ideologias formadoras de cultura política, que supõem a possibilidade, no capitalismo, de trabalhadores sem patrão, empreendedores e donos de seus próprios negócios como meio de alcançar melhores condições de vida e de trabalho.

Nesse sentido, a entrada do século XXI no Brasil expressa um contexto diferenciado de épocas anteriores, ao enaltecer e legitimar o trabalho precário nas formas de ocupações sem vínculos, empreendedorismo, terceirização e via trabalho temporário. O que está na pauta do dia é a luta pela sobrevivência, mediante atividades remuneradas pelo investimento em políticas de geração de emprego e transferência de renda, no enfrentamento ao desemprego e à pobreza, sob a cartilha da Política de Assistência Social. Para tanto, há um maior investimento na promoção do Programa de Aceleração do Crescimento (PAC), com ênfase na disponibilidade de recursos financeiros para os cidadãos brasileiros.

A necessidade de administrar as taxas elevadas de desemprego e controlar suas consequências políticas exigiu renovados mecanismos de enfrentamento por parte do Estado capitalista. De início, optouse por medidas que buscaram contribuir com o aumento do sistema de crédito, ganho no poder de compra, aumento relativo de trabalhadores com carteira assinada, incentivo ao empreendedorismo e política de valorização do salário mínimo. Esta realidade proporcionou ao país o lugar de sétima maior economia do mundo, conforme o DIEESE -Departamento Intersindical de Estatística e Estudos Socioeconômicos (2012).

Todavia, esta realidade não foi duradoura, pois as mudanças no interior do capitalismo brasileiro e as novas formas de gerir o trabalho não se mostraram capazes de responder efetivamente ao problema da recuperação das taxas de lucro e da resolução do desemprego e da pobreza por um longo período de tempo. É que a conjuntura brasileira apresentou, a partir de 2015, instabilidade na economia e na política, 
com muitos cortes na área social devido aos ajustes fiscais e à redução de custos. Esta realidade demonstra uma regressão do ponto de vista econômico e social, tendo como consequências: a) elevação nas taxas de juros; b) aceleração dos índices de inflação; c) redução dos serviços sociais; d) reforma na previdência; e) redução dos serviços prestados pela Política de Assistência Social.

O chamado mundo do trabalho passa a sofrer grandes impactos com as medidas de ajustes econômicos e sociais. A tendência é o aumento da instabilidade no trabalho. A instabilidade provocada pela crise mundial do capital agrava o problema do desemprego e o torna permanente, mesmo em momentos de recuo mediante investimentos na área social. Assim, conforme Mészáros (2013, p. 27), “[...] nenhum setor do trabalho está imune à miséria desumana do desemprego e do 'trabalho temporário"." Ainda esclarece: "[...] a questão não é se o desemprego ou o 'trabalho temporário flexível' vai ameaçar os trabalhadores empregados, mas quando estes, forçosamente, vão vivenciar a precarização" (MÉSZÁROS, 2006, p. 27).

Uma das tendências na administração do desemprego e das consequências dos problemas econômicos, sociais e políticos que o Brasil enfrenta é a legitimação da terceirização, que intensifica a precarização do trabalho via flexibilização.

Como uma das formas de enfrentar os problemas sociais e econômicos gerados pela instabilidade do trabalho, um dos objetivos da agenda da OIT, já no final do século XX, é a eliminação de todas as formas de discriminação em matéria de emprego e ocupação, tendo por base a Declaração dos Direitos e Princípios Fundamentais do Trabalho, de 1998. Esta estabelece o conceito de "trabalho decente" para homens e mulheres, recomendando a sua inserção no mercado de trabalho em condições de liberdade, segurança e equidade, numa estratégia que vela os antagonismos essenciais da exploração do trabalho e coloca em evidência a desestruturação do mercado de trabalho com o aumento da precarização.

Estas mudanças em curso têm como um dos propósitos atenuar a pressão que a superpopulação relativa, tal qual Marx (1984) analisou, exerce sobre o conjunto da classe trabalhadora. Visam exercer uma funcionalidade compensatória, pois, ao privilegiar os indivíduos com baixo poder aquisitivo, pela opção da raça ou da renda, tentam compensar esta parte da sociedade - o exército industrial de reserva - com o artificio ideológico da inserção necessária, que depende de o indivíduo ter capacidade de transformar-se em tipo ideal e/ou modelo de trabalhador desejado pelo capital, para acessar ao mercado.

\section{Contrarreforma e precarização: uma nova ofensiva contra o trabalho}

Desde os governos lulopetistas, o investimento em políticas de emprego, trabalho e renda para o enfrentamento do desemprego consistiu numa das alternativas para controlar os efeitos destrutivos no campo do trabalho, ao passo que a garantia do trabalho formal já não era mais o centro da intervenção do Estado. É que o desemprego, como uma das razões de existência do capitalismo, tornou-se um fenômeno de administração pela via da flexibilização dos processos e relações de trabalho, dada a acirrada precarização das condições de trabalho.

Com esse cenário forjou-se a conciliação de classes. Os trabalhadores e os mais pobres teriam vantagens, sem que fossem colocadas em risco a remuneração do capital e a reprodução do sistema.

No contexto da crise estrutural e do golpe parlamentar, institucional e midiático no Brasil, após o processo de impeachment de Dilma Rousseff, o atual presidente Michel Temer reduziu ministérios, editou a Medida Provisória 727, apresentou o pacote de contrarreforma da seguridade social, aprovou a prorrogação da Desvinculação das Receitas da União (DRU), extinguiu ministérios da área social, etc. Aprovou medidas que buscam congelar os investimentos sem contar, mais recentemente, com o lançamento do programa "Criança Feliz", que mostra a volta do primeiro-damismo e do assistencialismo, da desprofissionalização das políticas sociais e da negação do direito social.

Essas medidas são apresentadas como um imperativo técnico para "equilibrar" as contas públicas. Além do Estado mínimo, que se retira do fornecimento de serviços públicos, aponta para um regime tributário cada vez mais regressivo. Já há, no Brasil, um sistema de taxação que penaliza o trabalho e o 
consumo e beneficia os ganhos de capital. É uma política tributária que leva à concentração da renda e da riqueza.

Os intelectuais e defensores partidários alegam que, apesar de ser um remédio amargo, é a única saída para equilibrar as contas públicas e propiciar a mítica volta do crescimento econômico, criando um "ambiente favorável" aos investimentos privados e à retomada do emprego.

Na dinâmica cotidiana, observam-se amplos impactos regressivos que desde o golpe parlamentar vêm se intensificando no país. Amplia-se o sucateamento do Sistema Único de Saúde e da educação superior; a contrarreforma proposta pela mudança da previdência social intenciona aumentar e igualar a idade mínima para a aposentadoria de homens e mulheres (65 anos), sem levar em consideração as diferenças no que concerne às questões de gênero e à expectativa média de vida nas diversas regiões do país; há ainda a proposta de mudança para o recebimento do benefício de prestação continuada de 65 para 70 anos. Além disso, torna mais restritivas as regras de seguro-desemprego, numa época em que se verifica o crescimento do desemprego. O salário mínimo corre o grande risco de não mais obter ganhos reais.

Essas medidas expressam de forma contundente uma quebra nos principais direitos sociais assegurados pela Constituição Federal de 1988. O governo está autorizado a, por exemplo, não promover ou a vetar a realização de concurso público, ou a não autorizar aumentos de reposições salariais.

Atualmente, existem 27 projetos de lei tramitando no Congresso Nacional, cujo sentido consiste em eliminar ou limitar os direitos trabalhistas: a regulamentação da terceirização sem limite, que foi aprovada recentemente, busca a instituição do acordo extrajudicial de trabalho que permita a negociação direta entre empregado e empregador, assim como a suspensão de contrato de trabalho. Acrescentem-se a isso os ataques aos direitos previdenciários.

Desse modo, a limitação ou mesmo a eliminação de direitos sociais conquistados pelos trabalhadores, como o direito à aposentadoria, assim como os direitos à saúde e à educação pública e de qualidade, por meio da privatização dos gastos públicos, constituem prioridade para o governo. Basta observar, por exemplo, o corte de $20 \%$ e $30 \%$ nas bolsas do CNPq.

O que se tem, portanto, não é meramente uma questão matemática, mas uma questão de poder. Tanto que o "bolsa empresário" não sofrerá efeito negativo no ajuste, ou seja, as isenções fiscais que o governo tem empreendido acham-se fora deste cálculo. Assim, há um nítido favorecimento de relações paternalistas por meio de clientelismo, corrupção, financiamentos e disfarces assistencialistas.

Sob a administração do Estado, as atuais políticas de emprego, trabalho e renda são redimensionadas, caracterizando um novo tipo de emprego (termo utilizados pelas convenções da OIT), muitas vezes sem vínculos trabalhistas. Neste processo, a legitimação do trabalho precário torna-se uma nova tendência das políticas de emprego, trabalho e renda, como uma das formas de resposta ao desemprego.

A entrada dos anos 2000 no Brasil foi um cenário de relativa estabilidade propiciada pelas medidas anticíclicas do governo Lula. A aceleração da economia permitiu que o investimento financeiro e administrativo em políticas de emprego proporcionasse mudanças significativas no mercado de trabalho, com o investimento em microcrédito para trabalhadores que apresentavam vulnerabilidade social ou se achavam inseridos nas fileiras do desemprego.

Houve o aumento de postos de trabalhos, tanto no campo da formalidade quanto no campo da informalidade e das diversas ocupações cadastradas pelo Ministério do Trabalho e Previdência, mesmo sem a regulamentação das profissões.

As mudanças na economia brasileira e a intensificação da consolidação do trabalho atípico materializado na informalidade e no trabalho temporário conferiram novas tendências às políticas de emprego, trabalho e renda, submetidas às influencias das diretrizes da OIT. Com base nestas mudanças, passa-se a identificar uma das principais tendências dessas políticas no século XXI.

A intensa rotatividade dos trabalhadores formais (POCHMANN, 2008), as novas formas de ocupações e o incentivo do governo federal ao empreendedorismo são indicadores das mudanças no 
mercado de trabalho brasileiro na entrada do século XXI. Esta realidade aponta novas tendências na direção da construção das políticas iniciadas há duas décadas.

Uma das consequências das políticas de combate à inflação na agenda de vários governantes "levou à adoção de medidas voltadas à desestruturação do mercado de trabalho e à flexibilização dos contratos de trabalho" (POCHMANN, 2008, p. 112). Prova disso está nas várias modificações da legislação do trabalho que ocorreram ao longo dos anos, desde a sua promulgação em 1943. A atual proposta de reforma trabalhista traz à tona uma clara e explícita direção política conservadora e reacionária contra os trabalhadores e a favor dos empregadores e do capital.

A estratégia política posta por esta reforma revela-se com um discurso de modernização e agilidade para com as relações de trabalho no Brasil, visando instilar mais confiança aos empresários para negociar coletivamente com os trabalhadores sem acionar a Justiça do Trabalho e sem contar com o auxílio dos sindicatos. Para tanto, essa postulação ideopolítica falaciosa traz no seu cerne a ideia de que a CLT, que para seus idealizadores está desatualizada diante do atual cenário econômico e político que o país vivencia, necessita urgentemente de uma mudança que permita a redução dos processos de judicialização das causas trabalhistas.

A reforma trabalhista alterou artigos da CLT, com mudanças em 200 dispositivos, entre artigos e parágrafos, em que regulamentou, dentre várias questões, que o trabalhador arque com os efeitos da crise econômica, social e política que o país vivencia. Acirra, pois, a flexibilização e a insegurança jurídica para os direitos dos trabalhadores.

De modo que a Lei no 13.467, de 13 de julho de 2017, passa a alterar a consolidação das Leis do Trabalho (CLT), aprovada pelo Decreto-Lei no 5.452, de 1943, e as Leis 6.019, de 1974, além da 8.036, de 1990, e 8.212, de 1991, a fim de adequar a legislação às novas relações de trabalho que materializa a precarização e a desproteção do trabalho. Dentre algumas mudanças, destacam-se: as férias que poderão ser fracionadas em até três períodos, mediante negociação; trabalhadores e empresas poderão negociar todas as formas de remuneração, que não precisam fazer parte do salário; o plano de carreira poderá ser negociado entre patrões e trabalhadores sem necessidade de registro em contrato, podendo ser mudado constantemente; a modalidade do chamado trabalho intermitente, ou seja, por período, esse que não contemplava na legislação anterior, passa a ser possível, em que o trabalhador poderá ser pago por período trabalhado, recebendo pelas horas ou diária.

Além dessas mudanças, registra-se na nova lei o chamado trabalho remoto, ou home office, que consiste num teletrabalho, em que o controle do trabalho será realizado por tarefa. Cita-se, também, que os acordos coletivos poderão prevalecer sobre a legislação. Assim, os sindicatos e as empresas podem negociar as condições de trabalho diferentes das previstas em lei, mas não necessariamente em condições melhores para os trabalhadores. A nova lei também garante a contribuição sindical opcional e o trabalho de mulheres grávidas em ambientes considerados insalubres torna-se permitido. Registrase, ainda, que o banco de horas pode ser pactuado por acordo individual escrito, além de o trabalhador ser obrigado a comparecer às audiências na Justiça do Trabalho e, caso perca a ação, arcar com as custas do processo.

Essa contrarreforma já vinha sendo desenhada ao longo do contexto dos anos de 1990 no Brasil, ante os processos de reestruturação do trabalho. $O$ que a proposta de reforma trabalhista busca é assegurar a ampliação dos lucros dos empresários de forma negociada e juridicamente sancionada. Ampliase ainda mais o processo de flexibilização e precarização, que já vinha sendo implementado no país. Ou seja, a reforma passa a viabilizar legalmente o desmonte dos direitos do trabalho, o que na prática já se materializava.

Esse processo se dará de forma mais dinâmica e sem empecilhos, pois o trabalhador não terá a quem recorrer, já que o Estado, que em tese deveria assegurar tais direitos, passa a desresponsabilizar-se, transferindo toda e qualquer negociação aos empresários capitalistas. Prova disso está a atual contrarreforma proposta pelo governo de Temer, via PEC (Proposta de Emenda Constitucional) 287/16, constituindo uma reforma que busca abrir espaço ao mercado de capitais. De forma, que: 
[...] A previdência, por suas características contributivas, mensal e de largo prazo, revestese de importância impar aos capitais. A massa de capitais ali estocados é para alguns, oportunidades de investimentos, para outros é determinação das crises e, para a classe trabalhadora, é aumento da exploração (GRANEMANN, 2016, p.186).

A heterogeneidade do trabalho (ANTUNES, 2006), decorrente da dinamicidade do mercado com a disseminação do trabalho atípico (VASAPOLLO, 2006) e de outras formas ou modalidades de emprego, como a terceirização, o trabalho temporário, o trabalho por conta própria e a disseminação do empreendedorismo, redesenhou as políticas de emprego do século XXI de forma mais ampla, tornando-se regra geral.

As bases que redefinem o processo de construção da política de emprego com proteção e legitimidade a outras formas de inserções no mercado de trabalho decorrem das recomendações da Convenção 168 da OIT - Promoção do Emprego e Proteção contra o Desemprego.

Vigente no Brasil desde 1994, apesar de manter o discurso do pleno emprego, esta Convenção estabelece medidas e normas que visam garantir e promover todas as formas de emprego produtivo, incluindo as pequenas empresas, as cooperativas, o trabalho autônomo e as iniciativas locais em prol do emprego.

Na direção do que preconiza a Convenção 168, além do tripé - seguro-desemprego, intermediação de mão de obra e qualificação profissional - que fundamenta a política de emprego tradicionalmente desde a década de 1970 (DEDECCA, 2009), verifica-se um investimento, a partir da segunda metade da década de 1990, em programas direcionados a outras formas de emprego produtivo e de livre escolha que assegurem a sobrevivência do trabalhador, bem como de recursos destinados à transferência de renda e à promoção do emprego, sob a ideologia neoliberal.

A necessidade do crescimento estável através das políticas, o discurso da resposta flexível às mudanças no mercado de trabalho, o incentivo às novas modalidades de emprego e as novas regras dos direitos trabalhistas fornecem as bases para uma nova estrutura e direção das políticas de emprego. Nessa direção, a Resolução CODEFAT no 59, de 25 de março de 1994, institui o Programa de Geração de Emprego e Renda (PROGER), destinado especialmente aos trabalhadores de baixa renda, com o objetivo da geração do emprego e renda através da "concessão de linhas de crédito a setores com pouco ou nenhum acesso ao sistema financeiro convencional" (AZEVEDO, 1998, p. 145).

O PROGER, embora definido como uma política de emprego ativa, obedece a duas lógicas, conforme o Ministério do Trabalho e Previdência Social: tanto é um programa de crédito, ao seguir as orientações normativas das autoridades monetárias, como é um programa que se enquadra como uma política de emprego, porquanto que pode gerar emprego formal e ocupação alternativa para o trabalhador.

Atualmente, o programa investiu em recursos destinados à juventude com o objetivo de promover seu primeiro emprego. Nesse sentido, o PROGER adquiriu uma nova linha de crédito, com investimento de R\$ 5 bilhões para financiar capital de giro para micro e pequenas empresas, no intuito de preservar empregos e criar novas oportunidades para os jovens, especialmente no comércio e nos serviços.

Aprovado pelo Conselho Deliberativo do Fundo de Amparo ao Trabalhador (CODEFAT) e com recursos do BNDES, a nova medida assegura maior proteção aos jovens entre 18 e 24 anos, "cuja taxa de desemprego é superior a 18\%". Conforme o Ministério do Trabalho e Previdência Social, "esse segmento é mais suscetível à informalidade, à desigualdade de renda e ao desemprego".

Além do PROGER, o empreendedorismo brasileiro também conta com o Programa Nacional do Microcrédito Produtivo Orientado (PNMPO), instituído pela Lei no 11.110. As fontes de recursos disponibilizados pelo PNMPO são do FAT, acrescidos dos $2 \%$ dos depósitos compulsórios à vista junto ao Banco Central. Os recursos destinados às ações microempreendedoras são alocados nos bancos federais através de termos de depósitos especiais para esta finalidade. O Programa, além de financiar, incentiva e estimula palestras, seminários anuais e oficinas que discutam os desafios do microcrédito no país.

O investimento no empreendedorismo é uma das formas de intervenção para o desemprego que, além de estimular as ocupações, aumenta a lucratividade dos bancos com o incentivo ao sistema de crédito 
para o público popular. Com base na necessidade de ampliar a informação dos benefícios do empreendedorismo para o mercado financeiro e do trabalho, bem como sua adesão para o público desempregado, foi publicado pelo Portal Brasil, em 2015, o acordo entre o governo federal e o SEBRAE, incentivando o empreendedorismo, cuja parceria permitiu o treinamento de atendentes do SINE para prestar informações relacionadas aos pequenos negócios.

Os trabalhadores que procuram os serviços do SINE recebem instruções e orientações para abrir seu próprio negócio. Conforme o Portal, este acordo é inédito e promovido pelo Ministério do Trabalho e Emprego (MTE) em parceria com a Secretaria de Micro e Pequena Empresa (SMPE) e o Serviço Brasileiro de Apoio à Micro e à Pequena Empresa (SEBRAE), o qual tem duração de três anos. O público-alvo desses programas são os trabalhadores atendidos em ações de intermediação de mão de obra, com o propósito de recolocar esses profissionais no mercado de trabalho.

Além do benefício da geração de renda e oportunidade de trabalho para as camadas de baixa renda, esses programas são adequados às necessidades do mercado e transformam o trabalhador em empreendedor e o desempregado em autônomo ou trabalhador por conta própria.

O incentivo ao empreendedorismo reafirma a disseminação do autoemprego (POCHMANN, 1998), com vistas à abertura de pequenos negócios e de geração de emprego e renda e favorece a abertura de heterogêneas inserções ocupacionais que intensificam a precarização do mercado de trabalho e o mascaramento do número de desempregados.

A resposta ao desemprego, com políticas cada vez mais direcionadas ao trabalho por conta própria, legitima o trabalho precário sob o discurso da ampliação e promoção do trabalho em ocupações variadas, através de atividades autônomas. No intuito de promover a colocação dos trabalhadores em atividades autônomas e produtivas, o Sistema Público de Emprego é redimensionado para atender às determinações do mercado flexível brasileiro.

Esta realidade só reafirma a direção tendencial da políticas de emprego: a resposta ao desemprego via trabalho instável. Como já mencionado, a atual forma de amenizar a pressão da superpopulação relativa é intensificar um processo de precarização do trabalho travestido de inclusão produtiva para os trabalhadores supérfluos. Nas palavras de Antunes (2007, p. 17): “Estamos vivenciando, portanto, a erosão do trabalho contratado e regulamentado, dominante no século XX, e vendo sua substituição pelas diversas formas de 'empreendedorismo', 'cooperativismo', 'trabalho voluntário', 'trabalho atípico'".

Na perspectiva do empreendedorismo e do trabalho atípico, o discurso do Sistema Público de Emprego é integrar o emprego, trabalho e renda com vistas à equidade de inclusão dos trabalhadores, atendendo os grupos vulneráveis com maior dificuldade de inserção no mercado de trabalho. Para isso é estabelecida, também como princípio, a sustentabilidade financeira, a assegurar recursos adequados à viabilização do Sistema Público de Emprego, Trabalho e Renda, bem como à sua legalidade, definindo suas ações.

A OIT, ao considerar as dificuldades da "imperfeição da natureza" do mercado de trabalho - pela via da não produção do trabalho digno, dificuldades em políticas salariais eficazes e as disparidades entre o homem e a mulher em seus trabalhos, entre outros -, reconhece que o desemprego de longa duração e o aumento da informalidade são duas tendências difíceis de ser revertidas; por isso, persiste no esforço da manutenção e criação de novos empregos que não necessariamente estão no campo da formalidade.

A OIT lançou um documento intitulado "Para superar a crise: pacto mundial para o Emprego", na 98a Conferência Internacional, em 2009, para a América Latina e Caribe, com o objetivo de enfrentar a crise econômica e de emprego com políticas alinhadas ao Programa de Trabalho Decente da OIT.

Através da união entre os governos e da organização de trabalhadores e empregadores, o documento propõe medidas para manter as pessoas em seus trabalhos, apoiar os empregadores em seus investimentos e impulsionar a geração e recuperação dos empregos articulados aos sistemas de proteção social, especialmente para pessoas vulneráveis e conforme as particularidades de cada país.

Com o argumento de que as empresas e os empregos estão desaparecendo, o "Pacto Mundial para - Emprego" prioriza a necessidade de manter o trabalho e seus direitos na direção do trabalho digno; para isso, destaca algumas questões que devem ser objeto de intervenção dos governos da América Latina e 
Caribe, como: respeitar os direitos dos trabalhadores, valorizar as empresas sustentáveis, facilitar a mobilidade profissional e o acesso ao mercado de pessoas sem emprego, reforçar os serviços públicos de emprego e outras instituições para o mercado de trabalho, aplicar programas de formação profissional e aquisição de competências empresariais no estímulo de empregos dependentes e remunerados, investir na melhoria de qualificação profissional, reconhecer a contribuição das pequenas e médias empresas na criação de empregos onde haja a possibilidade de crédito para o desenvolvimento da empresa, reconhecer as cooperativas como fonte de trabalho e utilizar dispositivos públicos de garantia de emprego para o trabalho temporário.

Assim, ao lado do argumento da valorização dos direitos dos trabalhadores, é expressivo o incentivo a um tipo de trabalho que esteja condicionado ao mercado de trabalho flexibilizado, através do estímulo aos empregos dependentes e remunerados, no reconhecimento da necessidade do desenvolvimento das pequenas e médias empresas e do investimento em cooperativas, sob o rótulo da promoção ao emprego. Esta realidade faz parte do processo de desestruturação do mercado de trabalho, iniciado nos anos 1990.

As prioridades do "Pacto Mundial para o Emprego", através da manutenção do trabalho e a permanência dos direitos são, ao nosso ver, esvaziadas pela realidade contraditória do capitalismo diante do incentivo às diferentes formas de precarização do trabalho. Estas medidas que foram levantadas em âmbito internacional são mantidas e redefinidas na agenda do governo brasileiro, conforme as necessidades do mercado. Conforme Borges (2007, p. 85), o conjunto de transformações reconfigurou o mercado de trabalho brasileiro, tais como: "a baixa proporção de vínculos protegidos, a predominância de trabalho mal remunerado na estrutura ocupacional e a instabilidade dos vínculos".

Contraditoriamente, o discurso da proteção do trabalho continua central no direcionamento das políticas de emprego brasileiras. Através da parceria do SINE, do FAT, do MTPS e de outras instituições públicas que estão direcionadas à proteção do trabalho, são estabelecidas ações e programas que dão notoriedade às políticas de emprego, trabalho e renda no Brasil.

Com o propósito de aproximar as políticas de emprego da sociedade brasileira e atender um maior número de trabalhadores de variados perfis, foi instituído, em 2011, o portal "Mais Emprego" do MTPS. O Portal é um sistema informativo que integra ações e políticas de emprego, trabalho e renda para o melhor desempenho dos trabalhadores no mercado de trabalho, estabelecendo - além de outras atribuições uma relação entre empregadores e trabalhadores.

Para o empregador, este recurso é uma ferramenta que possibilita o envio de requerimento de seguro-desemprego, a disponibilização de vagas de emprego, a verificação do currículo de trabalhadores, o envio de demandas de qualificação, etc. Para os trabalhadores, são disponibilizadas "políticas e ações de emprego que se propõem a auxiliá-los na busca ou na preservação do trabalho decente, com qualidade e garantias trabalhistas e previdenciárias", bem como na verificação de oportunidades de vagas de emprego, cursos de qualificação ofertados, informações sobre o benefício abono salarial e a consulta e o cadastramento de ocupações pela Classificação Brasileira de Ocupações.

Uma grande parte dos programas e ações que compõem as políticas de emprego, trabalho e renda assume implicitamente em sua ideologia a defesa de contratos cada vez mais flexíveis, aliados às formas de desregulamentações de direitos trabalhistas, "[...] além, é claro, do empreendedorismo e da informalidade, acrescentando ser o caminho mais eficaz para estimular os índices de empregabilidade" (OLIVEIRA, 2012, p. 494).

Contraditoriamente, o caminho da construção das políticas de emprego do século XXI inviabiliza o discurso do trabalho decente da OIT, pois, a fim de atender à exigência cada vez de maior flexibilidade do mercado de trabalho, a saída para o problema do desemprego é a precarização do trabalho em detrimento da promoção ao emprego formal.

\section{A administração do desemprego pela via das contrarreformas: notas conclusivas}


Enquanto o desemprego é agravado, ainda se acham na pauta do dia estratégias que possam responder e garantir a redução do desemprego, tanto nos países centrais quanto nos periféricos, seja na forma de ampliação de políticas voltadas para o trabalho, seja por meio de demandas que favoreçam o campo político-econômico.

Como uma das formas de atender a parte das reivindicações da classe trabalhadora e contraditoriamente assegurar a manutenção das necessidades flexíveis do mercado, as ações do Estado são predominantemente direcionadas ao investimento em políticas ativas de emprego, por presumirem a garantia da promoção ao emprego. Estas políticas direcionam suas ações na qualificação dos trabalhadores desempregados, seja na formação inicial, seja na qualificação continuada.

$\mathrm{O}$ investimento cada vez maior em novos tipos de emprego desistoriciza e mascara os reais interesses da acumulação capitalista, que se estruturam a partir do controle do capital sobre o trabalho, ao transformar o trabalhador em empreendedor ou colaborador da empresa, retirando da cena política a luta dos trabalhadores enquanto classe e antagonista estrutural do capital. O direcionamento das políticas de emprego revela seu caráter contraditório, pois segue a diretriz da proteção dos direitos dos trabalhadores ao propor a necessidade do trabalho decente e de livre escolha, ao passo que direciona suas ações no incentivo ao trabalho autônomo, por conta própria, sob o discurso da promoção de novos tipos de emprego que não necessariamente possuam vínculos formais.

Nessa perspectiva, entende-se que a necessidade da implementação destas políticas tem como foco manter sob controle a pressão que o desemprego e/ou a superpopulação relativa exerce sobre o conjunto dos trabalhadores, ao requerer do Estado uma redefinição de suas ações que possam legitimar a administração do desemprego com o incentivo e o investimento financeiro em atividades empreendedoras, com o consentimento dos trabalhadores.

Destarte, a atual conjuntura, que expressa um trabalho cada vez mais desestruturado e heterogêneo, revela o desemprego como um fenômeno de difícil administração, pondo como estratégia do Estado a legitimação de novos tipos de empregos que possam assegurar as demandas da flexibilização do mercado e garantir a manutenção da força de trabalho. As diferentes formas de inserções no mercado, expressas no trabalho empreendedor, por conta própria e autônomo, evidenciam a precarização do trabalho sob o rótulo de promoção ao emprego decente e de livre escolha, reafirmando, assim, o caráter antagônico do sistema. Esta realidade denota a tendência das políticas de emprego, trabalho e renda do século XXI mediante os processos de precarização e flexibilização materializados pela contrarreforma dos direitos sociais e trabalhistas.

A partir do século XXI, como uma das formas de administrar o desemprego, o governo brasileiro investiu massivamente em políticas ativas e passivas de emprego através das chamadas medidas anticíclicas, a fim de buscar estratégias para o desenvolvimento do país, viabilizando emprego e ocupações das mais variadas formas: seja via empreendedorismo, seja via trabalho por conta própria, através de linhas de crédito e financiamentos, propiciando o consumo em massa. Estas medidas foram integráveis à economia brasileira por ampliarem o investimento nos setores privados através de cursos profissionalizantes/técnicos, além de garantir aos bancos estímulos para financiamentos e empréstimos à população.

Não se pode negar que as medidas anticíclicas do governo com o investimento em políticas e programas voltados para o trabalho funcionaram como uma possibilidade de sobrevivência para muitos brasileiros, restabelecendo a tentativa de um novo consenso mediante o aumento das ocupações. Entretanto, estas políticas e programas até o momento não garantiram um eficaz programa universal na direção do trabalho formal, especificamente. Tampouco têm como objetivo emancipar os indivíduos com o trabalho decente, como defende a OIT. Pelo contrário, estas políticas disseminam o investimento no trabalho precário e atípico, com o incentivo ao trabalhador empreendedor e por conta própria, reforçando o discurso de promoção do emprego no indivíduo.

Apesar de a garantia do trabalho formal continuar sendo o centro das discussões em âmbito internacional, é tendencial o predomínio de setores de atividades informais. Sob esta direção, as políticas mantêm uma íntima articulação com as necessidades da acumulação capitalista, seja do ponto de vista 
344

econômico, transformando ex-trabalhadores assalariados e socialmente protegidos em trabalhadores autônomos, terceirizados ou produtores simples de mercadorias, integrados às atuais estratégias de gestão da produção; seja socializando ideologias formadoras de cultura política que supõem a possibilidade, no capitalismo, de trabalhadores sem patrão, empreendedores e donos de seus próprios negócios, como meio de alcançar melhores condições de vida e de trabalho.

As inserções dos trabalhadores em vínculos precários e/ou sem nenhum tipo de regulação não se apresenta como algo novo na história do desenvolvimento capitalista. Marx, ao tratar dos trabalhadores da indústria nas diferentes formas de existência da superpopulação relativa, deixa claro que uma de suas categorias, denominada de estagnada, "[...] constitui parte do exército ativo de trabalhadores, mas com ocupação completamente irregular" (MARX, 1984, p. 208). Para o autor, a superpopulação relativa na sua forma estagnada constitui um reservatório inesgotável de força de trabalho disponível ao capital, cuja condição de vida está abaixo do nível médio da classe trabalhadora. Por esta razão, os trabalhadores inseridos de forma irregular no processo de produção se submetem a qualquer tipo de trabalho e salário.

Dessa forma, o grande desafio, diante do atual quadro político e econômico no Brasil, não é a unidade da esquerda, mas a construção da unidade da classe trabalhadora. Cumpre construir uma unidade política com ação concreta, o que exige organização coletiva e escolhas individuais. Precisa-se de uma frente única de luta, porque a conjuntura não é apenas conservadora e sim reacionária, e tem viabilizado que medidas neoliberais extremamente regressivas sejam adotadas. Por isso, insiste-se em dizer: nem um direito a menos!

\section{Referências}

ANTUNES, R. A era da informatização e a época da informalização: riqueza e miséria do trabalho no Brasil. In: Riqueza e miséria do trabalho no Brasil. São Paulo: Boitempo, 2006. p.15-25.

Dimensões da precarização estrutural do trabalho. In: DRUCK, Graça; FRANCO, Tânia (Orgs.). A perda da razão social do trabalho: terceirização e precarização. São Paulo: Boitempo. 2007. p. 13-22.

BRASIL. Ministério do Trabalho e Previdência Social. [Portal MTE]. Disponível em: < http://portal.mte.gov.br/portal-mte/rais/>. Acesso em: 20 maio 2016.

Resolução CODEFAT no 59, de 25 de março de 1994. Autoriza a alocação de recursos do FAT, excedentes da reserva mínima de liquidez em depósitos especiais. Disponível em: http://portalfat.mte.gov.br/wp-content/uploads/2016/01/Res59.pdf.

. Ministério do Trabalho e Previdência Social. Micro e pequenas empresas terão R\$5 bi do FAT para capital de giro. Brasília, 2016a. Disponível em: < http://mtps.gov.br/noticias/3375-micro-e-pequenas-empresas-terao-r-5-bi-do-fat-para-capitalde-giro>. Acesso em: 20 maio 2016.

. Ministério do Trabalho e Previdência Social. Fundo de Amparo ao Trabalhador. Programa de Proteção do Emprego (PPE). Brasília, 2016b. Disponível em: < http://portalfat.mte.gov.br/ programas-e-acoes-2/programa-de-protecao-do-emprego-ppe/>. Acesso em: 20 maio 2016.

Ministério do Trabalho e Previdência Social. O que é PROGER. Brasília, 2015.

DEDECCA, Claudio Salvadori. O sistema público de emprego e a estratégia de desenvolvimento. In: MACAMBIRA JÚNIOR; CARLEIAL, Liana M.F. (Orgs.). Emprego, trabalho e políticas públicas. Fortaleza: Instituto de Desenvolvimento do Trabalho, Banco do Nordeste do Brasil, 2009.

GRANEMANN; Sara. 0 desmonte das políticas de seguridade social e os impactos sobre a classe trabalhadora: as estratégias e a resistência. Palestra proferida durante o Seminário de Seguridade Social, 01 de dezembro de 2016, Universidade Estadual de Londrina, Paraná, 2016.

MARX, K. O capital. São Paulo: Abril Cultural, 1984.

MÉSZAROS, István. Desemprego e precarização: um grande desafio para a esquerda. In: ANTUNES, R. (Org.). Riqueza e miséria do trabalho no Brasil I. São Paulo: Boitempo, 2006.

OIT- ORGANIZAÇÃO INTERNACIONAL DO TRABALHO. Relativa à promoção do emprego e proteção contra o desemprego: convenção n. 168. Disponível em: < http://www.oitbrasil.org.br/node/479>. Acesso em: 2 maio 2016.

OLIVEIRA, Ednéia A. de. A política de emprego no Brasil: o caminho da flexinsegurança. Serviço Social e Sociedade, São Paulo, $n$. 111, 2012. p. 495-508.

POCHMANN, Marcio. As políticas de geração de emprego no Brasil. In: Reforma do estado: políticas de emprego no Brasil. Campinas: Unicamp, 1998. 
. Rumos da política do trabalho no Brasil. In: SILVA, Maria Ozanira da Silva e; YAZBEK, Maria Carmelita (Orgs.). Políticas públicas de trabalho e renda no Brasil contemporâneo. 2. ed. São Paulo: Cortez; São Luís: FAPEMA, 2008. p. 23-40.

VASAPOLLO, Luciano. $O$ trabalho atípico e a precariedade: elementos estratégicos determinantes do capital no paradigma pósfordista. In: ANTUNES; R. (Org.). Riqueza e miséria do trabalho no Brasil. São Paulo: Boitempo, 2006. p. 45-58.

${ }^{1}$ Termo utilizado por Antunes (1999). 